\title{
Fossil Horses, Orthogenesis, and Communicating Evolution in Museums
}

\author{
Bruce J. MacFadden • Luz Helena Oviedo • \\ Grace M. Seymour • Shari Ellis
}

Published online: 24 March 2012

(C) The Author(s) 2012. This article is published with open access at Springerlink.com

\begin{abstract}
The 55-million-year fossil record of horses (Family Equidae) has been frequently cited as a prime example of long-term macroevolution. In the second half of the nineteenth century, natural history museum exhibits characteristically depicted fossil horses to be a single, straight-line (orthogenetic) progression from ancestor to descendent. By the beginning of the twentieth century, however, paleontologists realized that, rather than representing orthogenesis, the evolutionary pattern of fossil horses was more correctly characterized by a complexly branching phylogenetic tree. We conducted a systematic survey of 20 fossil horse exhibits from natural history museums in the United States. Our resulting data indicate that more than half $(55 \%)$ of natural history museums today still depict horse evolution as orthogenetic, despite the fact that paleontologists have known for a century that the actual evolutionary pattern of the Family Equidae is branching. Depicting outmoded evolutionary patterns and concepts via museum exhibits, such as fossils horses exemplifying orthogenesis, not only communicates outmoded knowledge but also likely contributes to general misconceptions about evolution for natural history museum visitors.
\end{abstract}

Keywords Exhibits · Evolution · Fossil · Horses · Museum · Orthogenesis

B. J. MacFadden $(\bowtie) \cdot$ L. H. Oviedo $\cdot$ S. Ellis

Florida Museum of Natural History, University of Florida,

Gainesville, FL 32611, USA

e-mail: bmacfadd@flmnh.ufl.edu

G. M. Seymour

Cornell University,

Ithaca, NY 14853, USA

\section{Introduction}

Fifty million people visit natural history museums in the U.S. each year (MacFadden et al. 2007). These visitors expect to learn about current science and exciting discoveries and trust these institutions to communicate correct and up-to-date information (Falk and Dierking 2000; West 2005; Enseki 2006). Once inside the museum, many studies have shown that most visitors spend less than one minute at any given exhibit display (Cone and Kendall 1978; Donald 1991; Allen 2004), so museum scientists and exhibit developers are challenged to communicate science in a highly focused, engaging manner (Bell et al. 2009). This is oftentimes done with different combinations of specimens and artifacts, graphic displays, passages of text, and, more recently, multimedia technology (Hein 1998; Falk and Dierking 2000).

Many natural history museums and other informal sciencelearning institutions seek to communicate science content of societal relevance to the public, including current hot-button topics and of relevance to this study, evolution (NAS 2001; Diamond and Scotchmoor 2006). With regard to evolution, since the second half of the nineteenth century when many natural history museums were founded in the U.S., the fossil record of horses has frequently been depicted in exhibits communicating long-term (macro-) evolution (Gould 2002).

North America has been home to the horse family (Equidae) over the past 55 million years (since the Eocene epoch), and fossil horses are widespread on this continent during this time (MacFadden 1992, 2005). Nineteenth century paleontologists in the U.S. made extensive collections of fossil horses from the western territories that allowed them to piece together a sequence depicting horse evolution. As a result of the abundant fossil record and grand discoveries during the nineteenth century, fossil horses were prominently displayed in natural history museums that display evolutionary content (Clark 
2008; Dyehouse 2011; Fig. 1). Prominent twentieth century paleontologists such as George Gaylord Simpson (1944, $1953)$ and Stephen Jay Gould $(1988,2002)$ championed fossil horses as a prime example of evolution, and the popularity and potential impact of this group continues up to the present day (Franzen 2010).

\section{Evolution of Evolutionary Thought: Paleontology, Fossil Horses, and Orthogenesis}

A century ago, paleontologists typically depicted the evolutionary pattern of fossil horses in North America as a linear sequence from smaller ancestor to progressively larger descendent (Fig. 2), which fit well with a concept popular during the nineteenth century called orthogenesis, or "straight-line evolution" ("ortho-," Gr., straight, direct; "-genesis," Gr., origin). This concept, attributed to Haacke (1893) and other European scientists (Simpson 1944), carries along with it notions that evolution is progressive, represents improvement, and is predestined; these were accepted during that time, but, in modern scientific thought, they are not considered as part of the theoretical framework of macroevolution (MacFadden 1992; Gould 2002). Nevertheless, since that time, this pattern of the fossil horse lineage was embodied in museum displays (Clark 2008) and other media that communicated about evolution.
Thus, this sequence of fossil horses has been widely recognized as a classic, "textbook" example of evolution (Gould 2002; Dyehouse 2011). More than a half century ago, Simpson (1944, p. 157) stated that: "The most widely cited example of orthogenesis, in any sense of the word, is the evolution of the horse."

The problem with depicting fossil horses as orthogenetic is that, by the early twentieth century, paleontologists understood that, rather than a simple, straight-line sequence (Fig. 3A), the actual fossil record of horses was a complexly branching tree (Fig. 3B). The latter is exemplified by Gidley's (1907; Fig. 4 here) branching diagram of the subfamilies of fossil horses in which the Anchitheriinae overlaps in time with the Protohippinae during the late Miocene and the Protohippinae overlaps in time with the Equinae. In the orthogenetic model (and more recent concept of anagenesis), this overlap cannot occur as a macroevolutionary pattern because ancestral and descendant taxa (species) do not overlap in time, i.e., the former is replaced in time by the latter (Fig. 3). Following on the branching pattern, several decades later, Matthew (1930; Fig. 5) depicted the evolution of fossil horses with numerous genera and independent lineages that overlapped in time. This scheme was further elaborated upon by Simpson's (1951; Fig. 6) now widely cited horse phylogenetic tree, which continues in its essential pattern to the present day (MacFadden 1992, 2005 [Fig. 7]; Franzen 2010). Thus, to summarize our current state

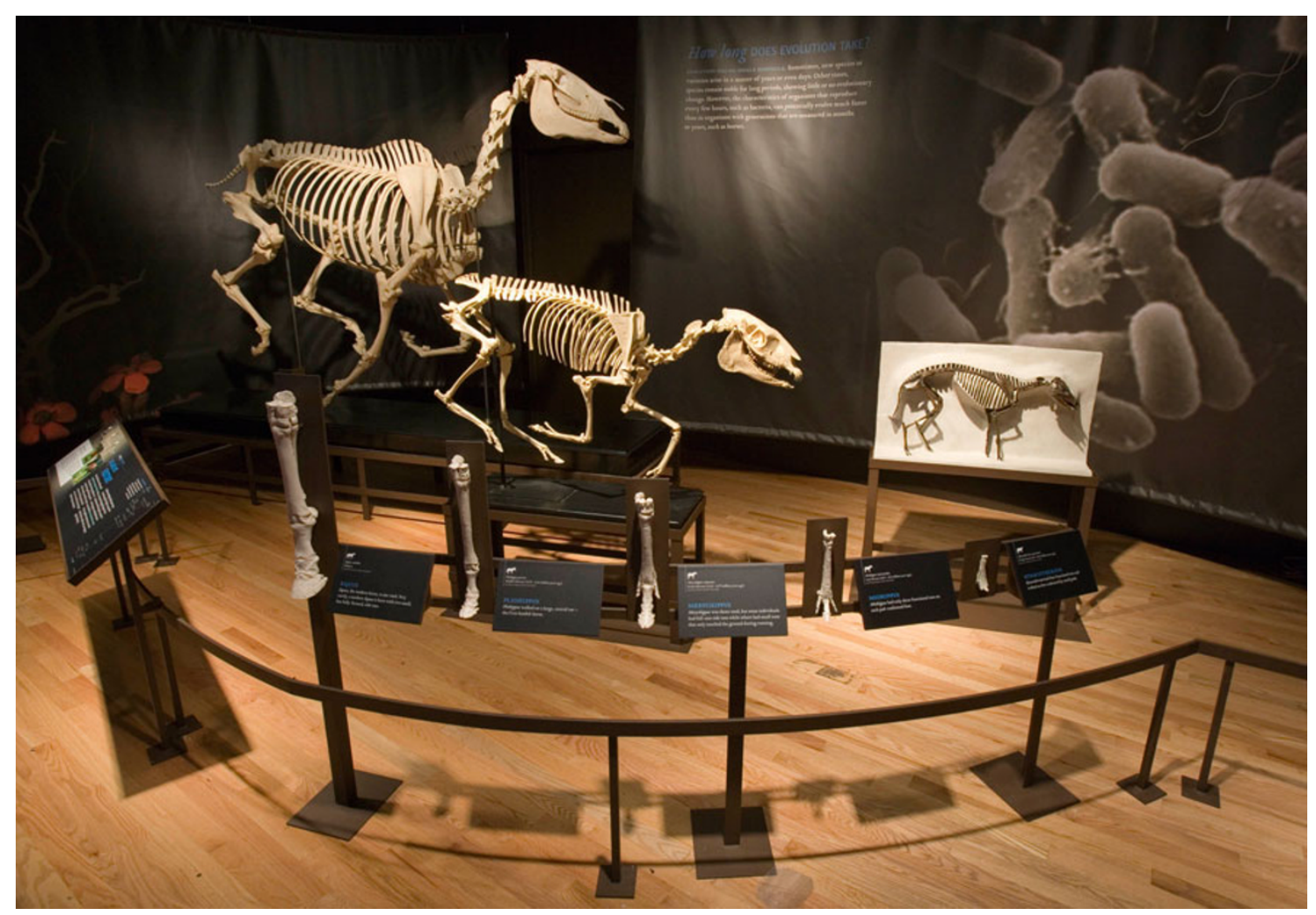

Fig. 1 Fossil horse exhibit, which is part of the Darwin travelling exhibit (Denis Finnin photo, reproduced with permission of the American Museum of Natural History, NY) 


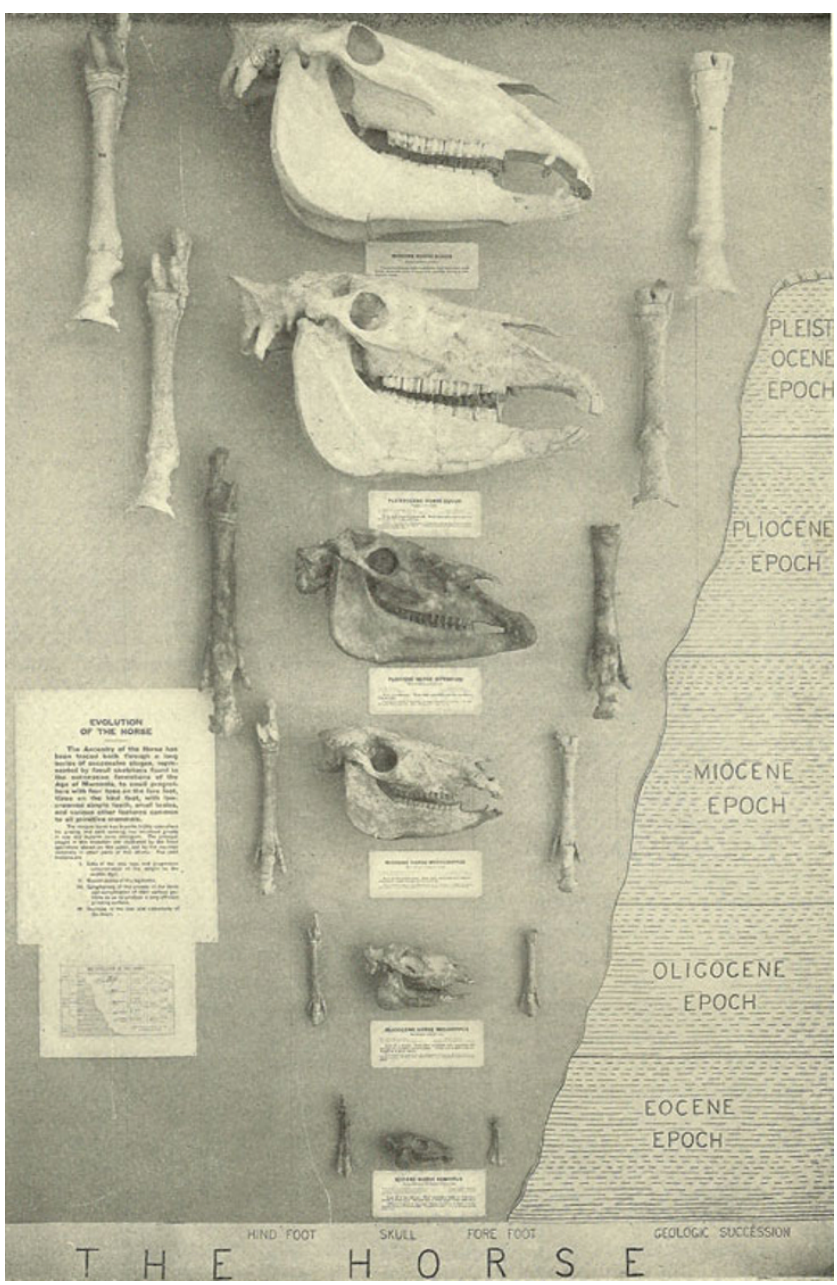

Fig. 2 Classic straight-line (orthogenetic) depiction of fossil horse evolution in a natural history museum exhibit in the early twentieth century (Matthew 1926). In this depiction, fossil specimens are arranged in a temporal sequence starting with the older fossil species of "eohippus" (Hyracotherium) at the bottom and ending with the genus of modern horse Equus at the top. In addition to depicting orthogenesis, this graphic display implicitly communicates nineteenth-century notions of evolution representing progress or improvement

of knowledge, instead of a linear sequence in which ancestral species evolve directly into their descendants, the evolutionary tree of horses is bushy, with many species overlapping in time, multiple originations, and frequent extinctions.

Despite this knowledge, to this day, the classic story of horse evolution in museums, books, and other media is still oftentimes depicted as orthogenetic. In addition to being factually incorrect within a modern scientific context of what we know about evolution, orthogenesis brings along with it baggage about evolution being largely progressive, deterministic, and representing improvement (MacFadden 1992; Gould 2002). These notions associated with orthogenesis therefore likely contribute to part of the general public's misunderstanding, or incomplete knowledge, about fundamental aspects of evolution (MacFadden 1992; Diamond and Scotchmoor 2006; Spiegal et al. 2006; MacFadden et al. 2007). In Jonathan Wells' (2000) book entitled Icons of Evolution: Science or Myth? Why much of what we teach about evolution is wrong, the author cites fossil horses as one of ten fundamental examples of evolution. He also accurately describes some of the problems associated with the miscommunication and states (Wells 2000, 195): "Since the 1950s, neo-Darwinian paleontologists have been actively campaigning to replace the old linear picture of horse evolution with the branching tree." As we will see below, this campaign has not been particularly successful.

We assert that, despite its roots in nineteenth century evolutionary theory, the outmoded scientific concept of orthogenesis is still widely communicated to the general public through various media, including natural history museum exhibits. We use fossil horses to test this hypothesis because of their widespread use as fundamental evidence for macroevolution (e.g., Gould 2002).

\section{Materials, Methods, and Research Design}

Based on a systematic review of natural history and science museums websites, we contacted staff at 36 institutions with current permanent or traveling exhibitions referring to evolution or fossil mammals requesting digital photographs of their horse evolution exhibits. Seventeen museums confirmed they currently had this type of exhibit. We received 91 photographs from these museums, including different views of the same exhibit. We ultimately selected 26 photographs based on quality and completeness. Three museums had online exhibitions; these were not contacted for photographs because we were able to access the exhibits directly. We considered only the graphic representation of horse evolution, and text descriptions were not included in the coding scheme because: (a) with only one minute or less for most visitors at a particular exhibit (Cone and Kendall 1978; Donald 1991), we assume that the text is not fully read; and (b) studies show information presented in exhibit text is less easily learned and recalled (Hooper-Greenhill 1994). Given what is known about general learning behavior (i.e., the time-tracking studies cited above), the visual impact of non-text exhibit components represents a significant factor in science communication; therefore, we contend that our concentration on graphics and related three-dimensional content (as opposed to the text) is justified. Each exhibit was evaluated to determine the number of components present. A component was defined as each array referring to horse evolution. For example, a set of skulls, feet, skeletons, or an image of horse evolution was considered a single component. Figure 8 shows one exhibit that we divided into three components. 
Fig. 3 A model to show the difference between orthogenesis (A) and branching (B) speciation (or phylogeny; from MacFadden 1992)

We used Content Analysis as the main methodology for this research because it is a way to study content in human communications such as text, images, maps, or symbols (Krippendorf 2004). A coding guide was developed and tested. A set of images with evolutionary depictions of species and taxa other than horses was used to assess reliability during training among two coders (Cohen's kappa 0.91; Cohen 1960). In the actual fossil horse exhibit data, coders independently rated each component as either orthogenetic or branching (Cohen's kappa 0.94). Once all elements of the exhibit were coded, each complete exhibit was then classified using a five-point qualitative scale: orthogenetic, primarily orthogenetic, mixed orthogenetic and branching, primarily branching, or branching. Exhibits, or exhibit components, were coded to be orthogenetic if there was no depiction of species overlapping in time, and if the species were depicted in a straight-line scheme, gradually growing in size and relative complexity (e.g., Fig. 1). Typically, the number of species displayed in orthogenetic displays was fewer compared with branching displays. Exhibits, or exhibit components, were considered to be branching if there was a clear tree with the same emphasis on all species and/or evidence of coexistence of species (e.g., Fig. 7). Exhibit components that mixed these patterns were coded as mixed orthogenetic and branching (e.g., Fig. 9).

For exhibits with more than one component, the approach, size, and location of each unit were qualitatively assessed by each coder. Intercoder reliability on the overall assessment was 0.7 using Cohen's kappa (Cohen 1960), and it was considered appropriate (Landis and Koch 1977; Lombard et al. 2002). Disagreements were discussed and resolved (Lombard et al. 2002). In total, we analyzed 37 components within 20 physical
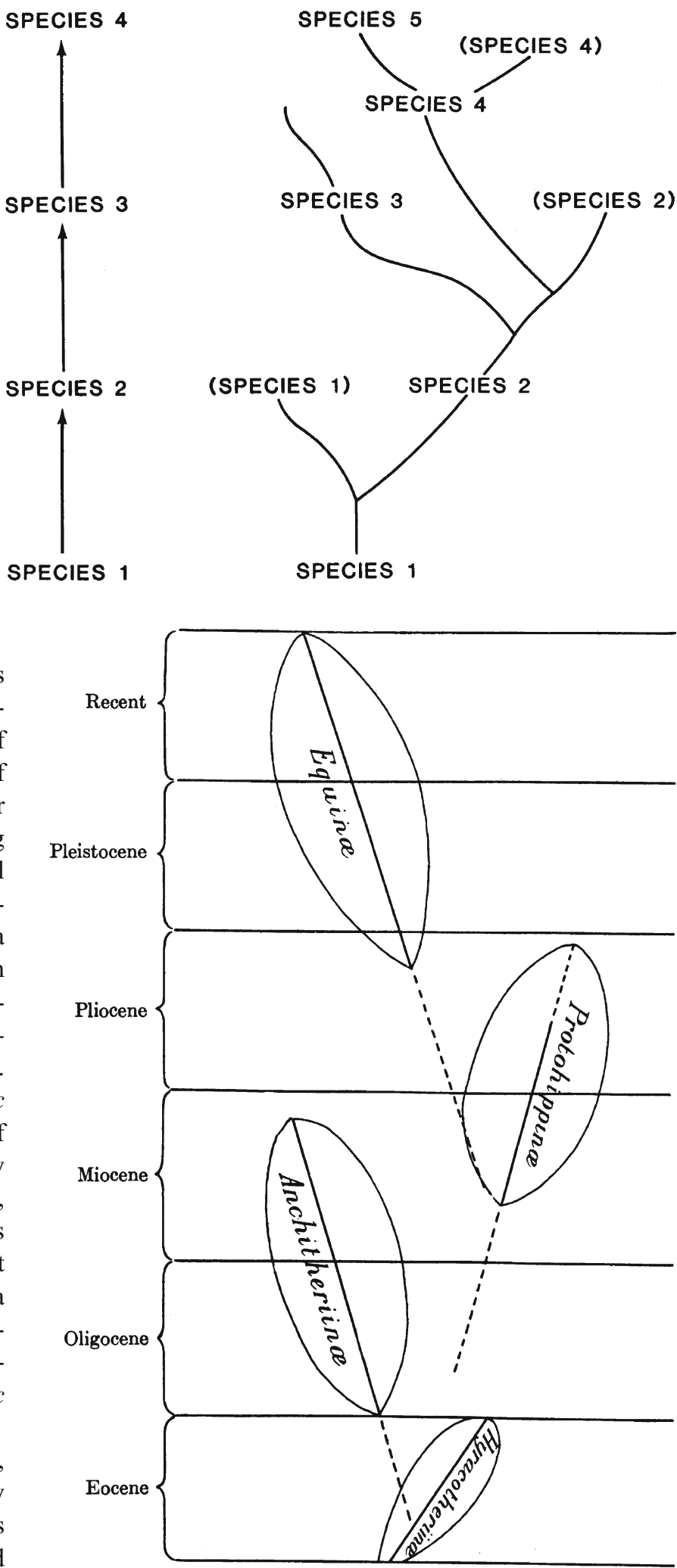

Fig. 4 Gidley's (1907) phylogeny of the subfamilies of fossil horses from North America showing some overlap, which thereby negates orthogenesis as an evolutionary mode 


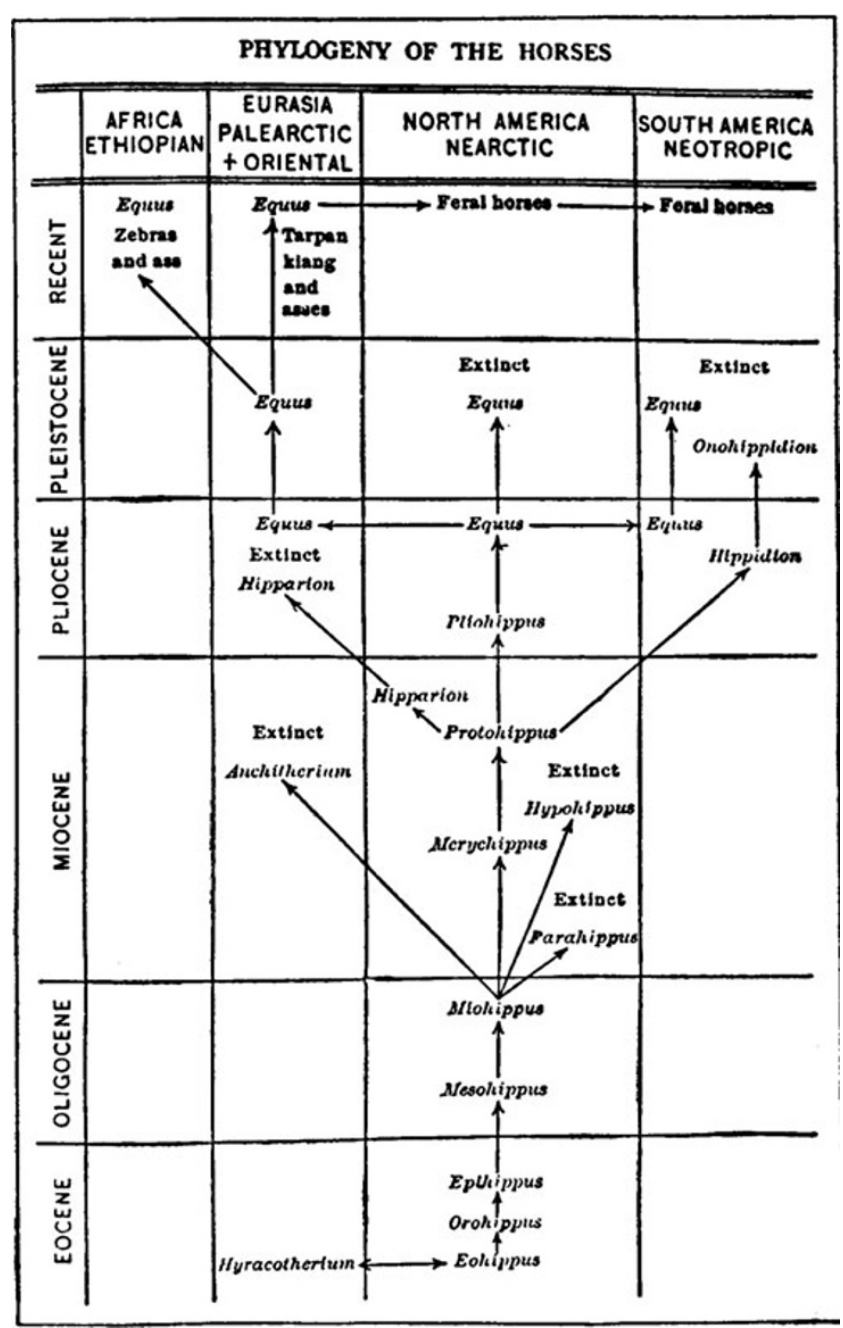

Fig. 5 Matthew's (1930) horse phylogeny, published in the popular magazine Scientific American, showing significant branching of numerous genera

and online exhibits depicting fossil horses in the United States (Table 1).

\section{Results and Discussion}

Our survey data demonstrate that within fossil horse exhibits, the orthogenetic pattern is the most common type of depiction in both individual exhibit components $(62 \%)$ as well as complete exhibits (40\%, Fig. 10). Moreover, when orthogenetic and primarily orthogenetic exhibits are grouped, they represent $55 \%$ of the total sample; exhibits considered to be mixed orthogenesis and branching represent 20\%; and the branching and primarily branching groups combined represent the remaining $25 \%$. We therefore conclude from these data that orthogenesis is a widespread depiction in fossil horse exhibits in U.S. natural history museums today.
Given these results, why is orthogenesis so prevalent in current fossil horse exhibits, when paleontologists have known for a century that it is an incorrect way to depict the pattern of horse evolution? We contend that the answer to this question is complex and likely involves multiple factors, including:

1. An inability and inertia of researchers studying fossil horses to effectively communicate to other scientists (particularly outside of their discipline), museum curators, exhibit designers, text-book authors, and the public. As demonstrated above, knowledge that the evolutionary pattern of fossil horses is branching has been current for a century, but this fact has not been effectively communicated outside the narrow sphere of practicing professional paleontologists.

2. Museum exhibits are expensive to build, particularly in grand exhibition halls costing millions of dollars. For example, the Hall of Florida Fossils: Evolution of Life and Land at the Florida Museum of Natural History was completed in 2004 at a cost of about $\$ 2.5$ million dollars, which equates to about $\$ 600$ per square foot. This is fairly

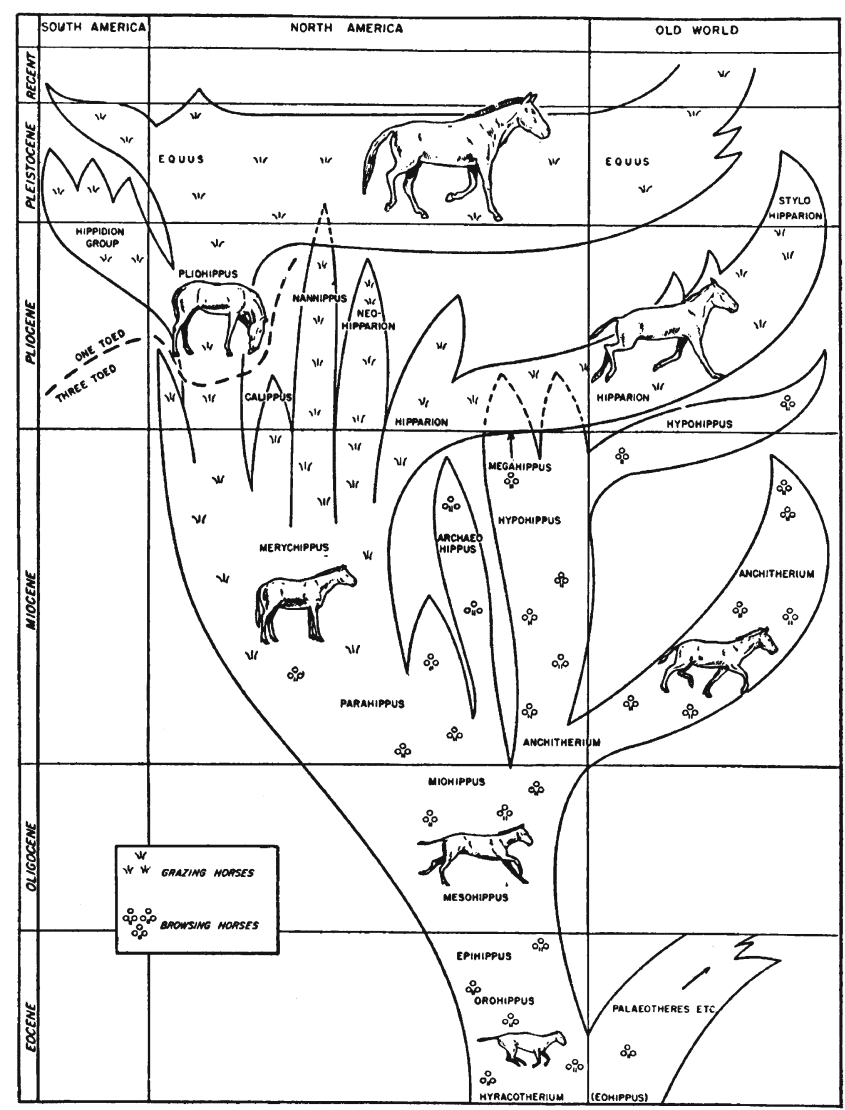

Fig. 6 Simpson's (1951) horse phylogeny that elaborates upon previous workers such as Matthew and represents the principal pattern of macroevolution of the Family Equidae that is elaborated upon up to the present day 


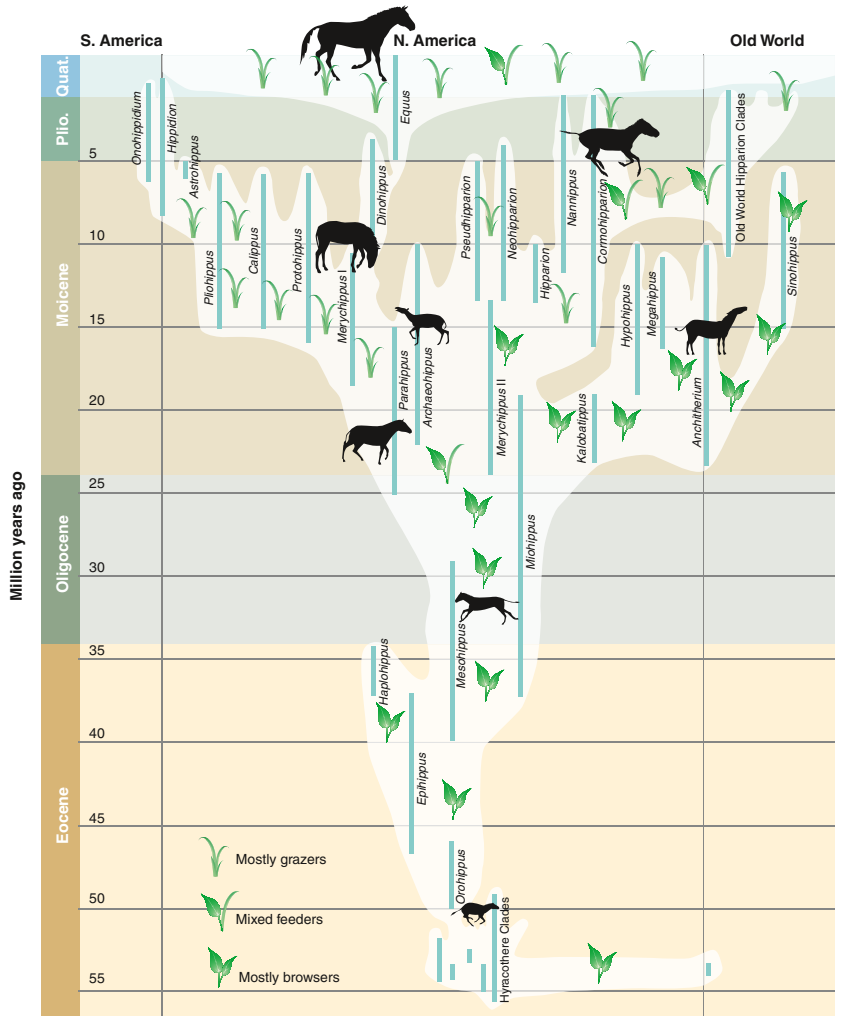

Fig. 7 Phylogeny of the Family Equidae based on a recent updated graphic (MacFadden 2005). Reproduced, with permission from the American Association for the Advancement of Science

typical for a multimedia, specimen-rich major exhibition hall. Accordingly, and from a pragmatic point of view, after the rush of activity passes with newly opened exhibit halls, museum professionals typically move on to the next project, and therefore physical renovations and scientific updates to prior projects are slow to be implemented. It therefore is a challenge to incorporate the most current scientific concepts into physical exhibits (although with modern multimedia displays and cyberexhibits, this inertia has the potential to change in the future). Moreover, as Dyehouse (2011) has shown, even when museum curators are sensitive to the issue of public perception of orthogenesis, this pattern or schema may unintentionally become incorporated into updated physical exhibits.

3. With only a minute or less for learning opportunities at individual exhibits, museum interpretive content graphics are frequently presented in a simplified manner, e.g., with orthogenesis rather than a branching schema. Studies of museum visitors, however, show that, when abstract concepts are oversimplified, misconceptions can result (Bishop and Anderson 1990; Matuk and Uttal 2008). Thus, within the context of our study, we assert that orthogenetic depictions provide incorrect information for the sake of simplicity and also lead to fundamental misconceptions about the pattern of macroevolution.

4. Research from the cognitive and learning sciences demonstrates that common ways of visually representing evolution contribute to fundamental misconceptions, especially among people with less well-developed backgrounds in science, i.e., where intuition results in a naïve conception framework for learning. Of relevance to the current study, depictions that utilize vertical space with more recent developments placed at the top imply progress or improvement and lead individuals to conceive of evolution as a teleological (purpose-driven) process (Tversky 2011). Furthermore, linear depictions encourage anagenic (direct sequence from ancestor to descendent) interpretations of speciation (Catley et al. 2010; Novick et al. 2011).

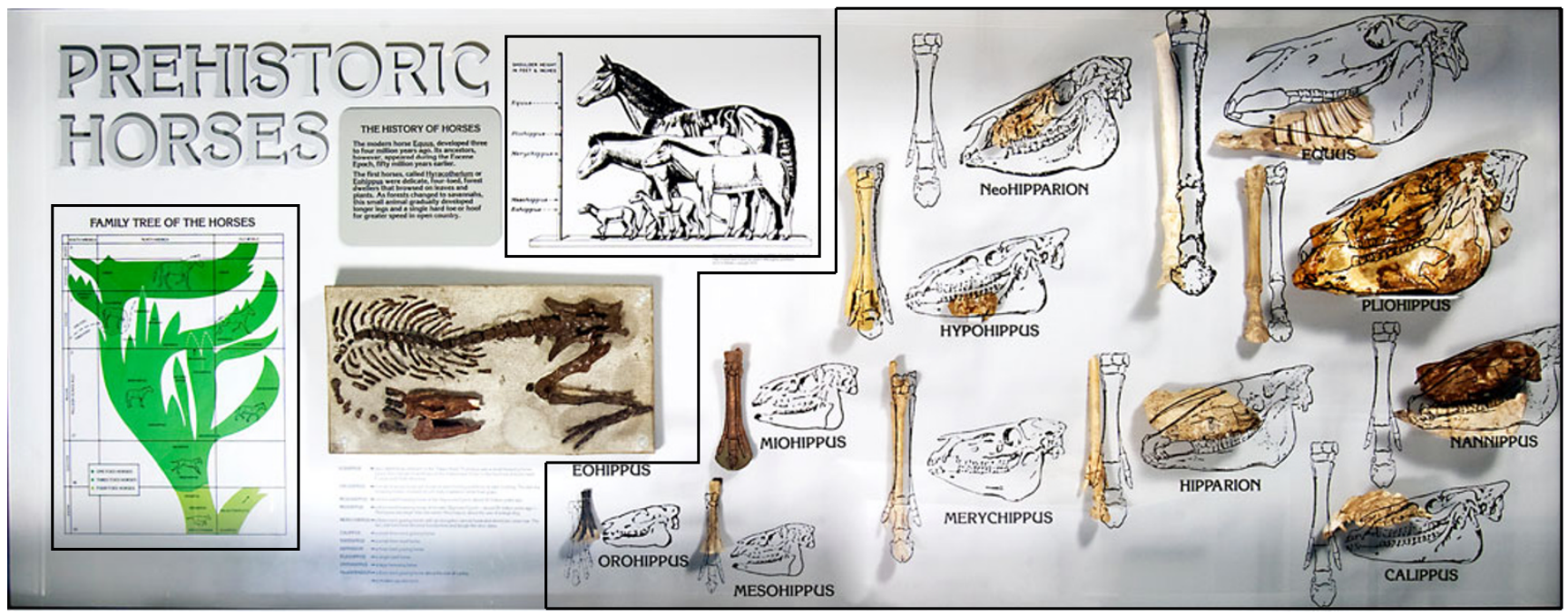

Fig. 8 Horse evolution exhibit at the Panhandle Plains Historical Museum, Canyon, Texas, showing the three individual components (indicated in the black boxes) that we coded during our study. Reproduced with permission 


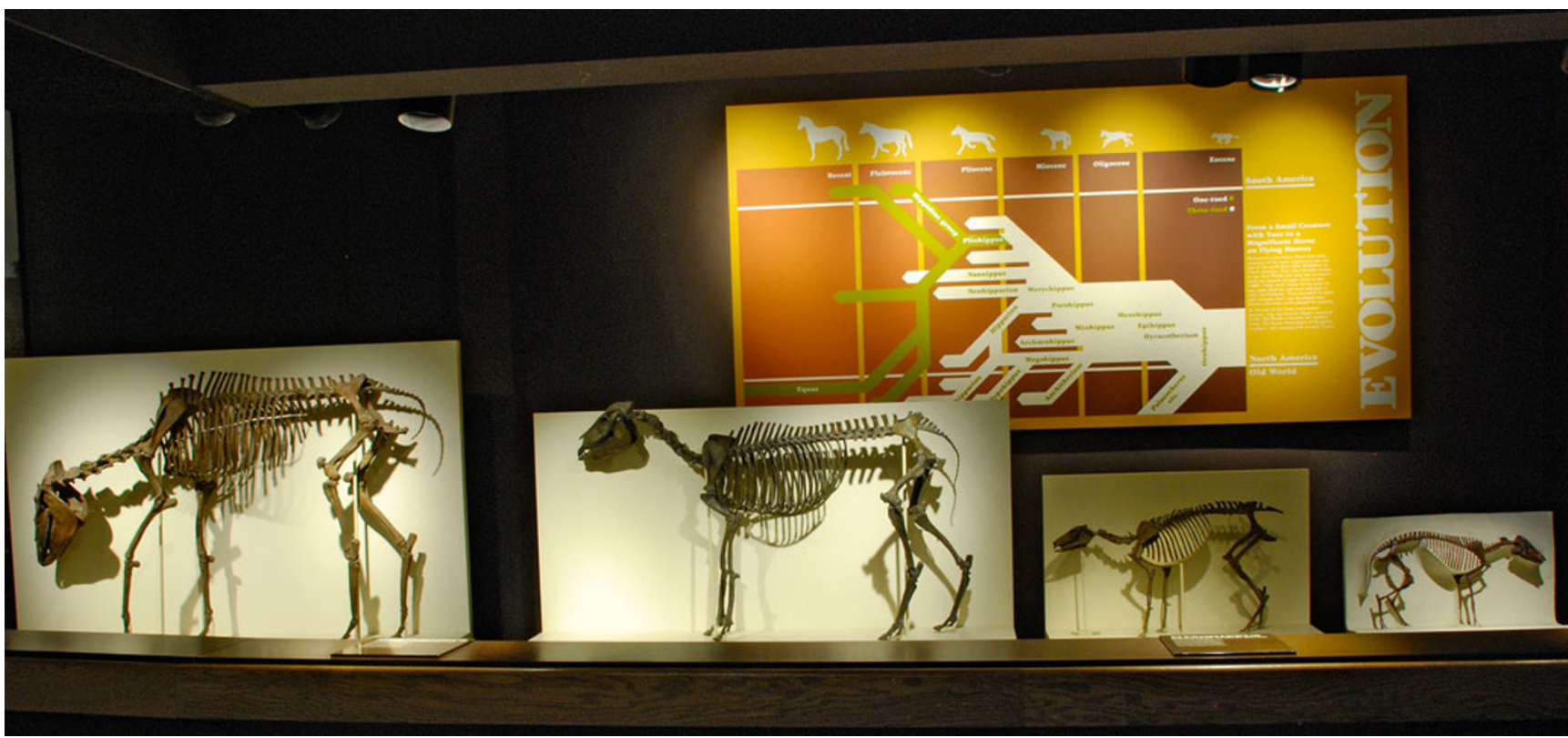

Fig. 9 Horse evolution exhibit currently on display at the International Museum of the Horse, Kentucky Horse Park, Lexington, KY. This exhibit mixes components that communicate orthogenesis (the skeletons arranged in the foreground) along with branching evolution (the phylogenetic tree graphic behind the skeletons). Reproduced with permission

Table 1 Classification of fossil horse exhibits and museums included in the study

\begin{tabular}{|c|c|c|c|c|}
\hline Museum & State & Number of displays & Pattern of depiction & Yearly attendance \\
\hline University of Nebraska State Museum & $\mathrm{NE}$ & 1 & $\mathrm{O}$ & 86,182 \\
\hline Field Museum of Natural History & IL & 2 & $\mathrm{O}$ & $1,212,475$ \\
\hline Harvard Museum of Natural History & MA & 1 & $\mathrm{O}$ & 150,000 \\
\hline U.S. National Museum of Natural History, Smithsonian Institution & $\mathrm{DC}$ & 1 & $\mathrm{O}$ & $5,542,000$ \\
\hline Darwin (traveling exhibit ${ }^{\mathrm{a}}$ ) & $\mathrm{N} / \mathrm{A}$ & 2 & $\mathrm{O}$ & N/A \\
\hline Amherst College, Beneski Museum of Natural History & MA & 1 & $\mathrm{O}$ & 25,000 \\
\hline $\begin{array}{l}\text { Kansas University Natural History Museum and Biodiversity } \\
\text { Research Center }\end{array}$ & KS & 2 & $\mathrm{O}$ & 46,000 \\
\hline American Museum of Natural History & NY & 1 & $\mathrm{O}$ & $4,000,000$ \\
\hline Carnegie Museum of Natural History & PA & 1 & $\mathrm{PO}$ & 497,000 \\
\hline Natural History Museum of Los Angeles County & $\mathrm{CA}$ & 1 & $\mathrm{PO}$ & 650,000 \\
\hline Peabody Museum of Natural History & $\mathrm{CT}$ & 4 & $\mathrm{PO}$ & 145,000 \\
\hline International Museum of the Horse & KY & 2 & M & 200,000 \\
\hline University of Michigan Museum of Natural History & MI & 2 & M & 7,000 \\
\hline University of Oregon Museum of Natural and Cultural History & OR & 4 & M & 200,000 \\
\hline University of California Museum of Paleontology-Berkeley & $\mathrm{CA}$ & 2 & M & b \\
\hline Florida Museum of Natural History & FL & 3 & $\mathrm{~PB}$ & 275,000 \\
\hline Denver Museum of Nature and Science & $\mathrm{CO}$ & 1 & $\mathrm{~PB}$ & $1,252,300$ \\
\hline Santa Barbara Museum of Natural History & $\mathrm{CA}$ & 1 & $\mathrm{~PB}$ & 110,000 \\
\hline The Horse (traveling exhibit ${ }^{\mathrm{a}}$ ) & N/A & 1 & $\mathrm{~B}$ & $\mathrm{~N} / \mathrm{A}$ \\
\hline Panhandle Plains Historical Museum & $\mathrm{TX}$ & 3 & $\mathrm{~B}$ & 75,000 \\
\hline Total summed yearly attendance & & & & $14,472,957$ \\
\hline
\end{tabular}

The attendance figures for each museum were taken from AAM (2007). The cumulative attendance figures for the two travelling exhibits were not available (n/a), and those for the three Web exhibits are not reported

$O$ orthogenetic, $P O$ primarily orthogenetic, $M$ mixed (equally orthogenetic and branching), $P B$ primarily branching, $B$ branching

${ }^{a}$ Developed by The American Museum of Natural History, New York

b 1.2 million Web visitors per month according to University of California at Berkeley; not included in total summed yearly attendance 

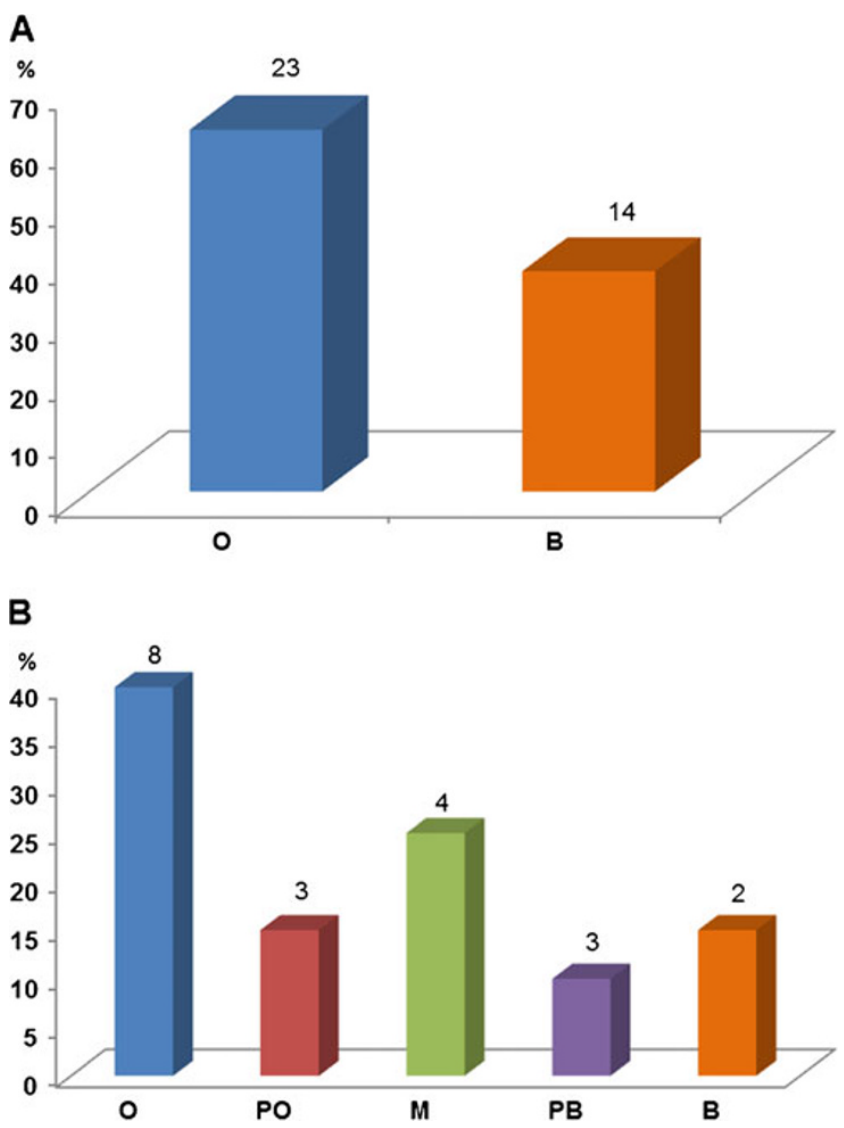

Fig. 10 Distribution of fossil horse displays in natural history museums communicating orthogenesis versus branching patterns of evolution. a Orthogenesis versus branching in the 37 individual components analyzed. b Overall pattern of evolution depicted in multi-component exhibits from 20 museums (see Table 1). Abbrev: $O$, orthogenetic; $P O$, primarily orthogenetic; $M$, mixed $O$ and $B ; P B$, primarily branching; $B$, branching. Numbers at the top of each bin represent sample size $(N)$

Other research has shown that branching-tree depictions that accurately represent macroevolutionary patterns are difficult for students and museum visitors to grasp (Gregory 2008; Evans et al. 2010). The solution, we contend, is not to settle for simpler, more accessible museum displays. Inappropriate depictions of evolution in museums should be no less accurate than their textbook counterparts (Catley and Novick 2008). The 15 institutions surveyed here that depict horse evolution as either orthogenetic, primarily orthogenetic, or mixed have an estimated visitation of more than 12 million people per year (Table 1) to their physical exhibits (when cyberexhibits are added, this figure would be greater). While we do not assert that every visitor to each of these institutions saw the horse evolution exhibit, the potential exists for scientific miscommunication on a large scale, which likely contributes to the low public acceptance, and generally poor understanding, of evolutionary concepts in the U.S (Miller et al. 2006).
We have used fossil horse exhibits as an example of orthogenesis, yet the impact of this cognitive framework is pervasive and extends to other organisms, both living and extinct, including humans (Scott and Guisti 2006). The common quip among the non-believing general public, "Don't tell me I'm descended from a monkey," derives from an orthogenetic framework in which humans evolved directly from apes. The impact of orthogenesis also transcends museum exhibits and can be found in many other media that communicate about science, including textbooks, newspapers, magazines, documentaries, and the enormous access provided by the Web. This lack of public understanding of evolution in the U.S. has profound consequences for overall understanding within the life and natural sciences and also impacts applied aspects of society, such as human medicine.

\section{Concluding Comments}

While the scope of our study concentrated on natural history museums in the U.S., anecdotal evidence (MacFadden, personal observations; also see, e.g., Franzen 2010, but no comprehensive list is currently available) suggests that orthogenetic frameworks are widespread in museums in other countries, and this pattern is not just found in fossil horses exhibits, but in many other kinds of depictions, particularly involving evolutionary sequences and interpreted phylogenies of groups with a fossil record. The magnitude and pervasiveness of this style of content presentation thus results in a worldwide challenge for science communication and science literary.

Science evolves with the advent of new discoveries and ongoing research, as is the case for the classic story of fossil horse evolution that has developed over the past 150 years. Despite the scientific discoveries that paleontologists have made "in the trenches," these advances in knowledge have been slow to enter into the general body of scientific knowledge about evolution. One consequence of this inertia has been that natural history museum exhibits have been slow to incorporate recent scientific advances into the content of their exhibits. Misinformation communicated in this manner likewise contributes to the museum visitors' misunderstanding about fundamental concepts and examples of evolutionary theory. If science literacy is a priority in modern society and the public needs to make informed decisions in their everyday lives that depend upon understanding evolution, then it is incumbent on scientists and museum professionals to more effectively communicate in media such as museum exhibits.

Acknowledgments We thank our contacts at the museums surveyed for providing exhibit photographs. This research was partially supported by U.S. National Science Foundation (NSF 09-66884, OISE, EAR, OISE), Vertebrate Paleontology Fund, Florida Museum of Natural History, and student scholarships provided by the Fossil Club of Lee County and Southwest Florida Fossil Club. 
Open Access This article is distributed under the terms of the Creative Commons Attribution License which permits any use, distribution, and reproduction in any medium, provided the original author(s) and the source are credited.

\section{References}

AAM (American Association of Museums). The Official Museum Directory, 38th Edition. New Providence New Jersey: National Register Publishing; 2007.

Allen S. Designs for learning: studying science museum exhibits that do more than entertain. Sci Educ. 2004;88 Suppl 1:S17-33.

Bell P, Lewenstein B, Shouse AE, Feder MA, editors. Learning science in informal environments: people, places, and pursuits. Washington DC: National Academies Press; 2009.

Bishop B, Anderson C. Student conceptions of natural selection and its role in evolution. J Res Sci Teach. 1990;27:415-27.

Catley KM, Novick LR. Seeing the wood for the trees: an analysis of evolutionary diagrams in biology textbooks. BioScience 2008; 58:976-987.

Catley KM, Novick LR, Shade CK. Interpreting evolutionary diagrams: when topology and process conflict. J Res Sci Teach 2010; 47:861882.

Clark CA. God-or gorilla: images of evolution in the Jazz Age. Baltimore: The Johns Hopkins University Press; 2008.

Cohen J. A coefficient of agreement for nominal cases. Educ Psychol Meas. 1960;20:137-46.

Cone CA, Kendall K. Space, time, and family interaction: visitor behavior at the Science Museum of Minnesota. Curator. 1978;21:245-58.

Diamond J, Scotchmoor J. Exhibiting evolution. Mus Soc Issues. 2006;1:21-48.

Donald JG. The measurement of learning in the museum. Can J Educ. 1991;16:371-82.

Dyehouse J. "A textbook case revisited": visual rhetoric and series patterning in the American Museum of Natural History's horse evolution displays. Tech Commun Quart. 2011;20:327-46.

Enseki C. Public trust and accountability. New Standard. Washington DC: American Association of Museums; Summer 2006.

Evans M, Frazier B, Hazel A, Kiss A, Lane JD, Spiegal A, Diamond J. Tree thinking: do pictorial representations of phylogenetic relationships help or hinder museum visitors' understanding of evolution? Abstract of talk presented at the Tree of Life Conference, Carnegie Museum of Natural History (August 2010).

Falk J, Dierking L. Learning from museums. Walnut Creek, CA: AltaMira Press; 2000.

Franzen JL. The rise of horses. Baltimore: The Johns Hopkins University Press; 2010.

Gidley JW. Revision of the Miocene and Pliocene Equidae of North America. Bull Am Mus Nat Hist. 1907;23:865-934.
Gould SJ. The case of the creeping fox terrier clone. Nat Hist. 1988;97:16-24.

Gould SJ. The structure of evolutionary theory. Cambridge, MA: Harvard University Press; 2002.

Gregory TR. Understanding evolutionary trees. Evo Edu Outreach. 2008;1:121-37.

Haacke W. Gestaltung und Verebung. Leipzig: Weigel; 1893.

Hein GE. Learning in the museum. New York: Routledge; 1998.

Hooper-Greenhill E. Museums and their visitors. New York: Routledge; 1994.

Krippendorf K. Content analysis. An introduction to its methodology. Thousand Oaks, CA: Sage Publications; 2004.

Landis R, Koch G. The measurement of observer agreement for categorical data. Biometrics. 1977;33:159-74.

Lombard MJ, Snyder-Duch J, Campanella C. Content analysis in mass communication. Assessment and reporting of intercoder reliability. Human Commun Res. 2002;28:587-604.

MacFadden BJ. Fossil horses: systematics, paleobiology, and evolution of the Family Equidae. Cambridge: Cambridge University Press; 1992.

MacFadden BJ. Fossil horses - evidence for evolution. Science. 2005;307:1728-9.

MacFadden BJ, Dunckel B, Ellis S, Dierking L, Abraham-Silver L, Kisiel J, Koke J. Natural history museum visitors' understanding of evolution. Biosci. 2007;57:875-82.

Matthew WD. The evolution of the horse: a record and its interpretation. Quart Rev Biol. 1926;1:139-85.

Matthew WD. Pattern of evolution. Sci Am. 1930;143:192-6.

Matuk C, Uttal D. Entertaining evolution: understanding evolution from animations. Proc 8th Int Conf Learn Sci. 2008;3:93.

Miller JD, Scott EC, Okamoto S. Public acceptance of evolution. Science. 2006;313:765-6.

National Academy of Sciences. Science, evolution, and creationism. Washington, DC: NAS; 2001.

Novick LR, Shade CK, Catleyb KM. Linear versus branching depictions of evolutionary history: implications for diagram design. Top Cogn Sci. 2011;3:536-59.

Scott M, Guisti E. Designing human evolution exhibitions: insights from exhibitions and audiences. Mus Soc Issues. 2006;1:49-67.

Simpson GG. Tempo and mode in evolution. New York: Columbia University Press; 1944.

Simpson GG. Horses: the story of the horse family in the modern world and through sixty million years of history. New York: Oxford University Press; 1951.

Simpson GG. The major features of evolution. New York: Columbia University Press; 1953.

Spiegal AN, Evans M, Graham W, Diamond J. Museum visitors' understanding of evolution. Mus Soc Issues. 2006;1:69-85.

Tversky B. Visualizing thought. Top Cogn Sci. 2011;3:499-535.

Wells J. Icons of evolution: science or myth? Why much of what we teach about evolution is wrong. Washington DC: Regnery Publishing; 2000.

West R. The lay of the land: the current context for communicating evolution in natural history museums. Rep Natl Cent Sci Educ. 2005;25:21-5. 